\title{
Treatment of Patients with Glioblastomas by Low Concentrations of Verapamil Hydrochloride in the Late Postoperative Period
}

\author{
Nina Gridina ${ }^{1}$, Anatoliy Morozov², Yuriy Ushenin ${ }^{3}$, Vladimir Rozumenko ${ }^{4}$, Nataliya Draguntsova ${ }^{5}$ \\ ${ }^{1}$ Experimental Department, Romodanov Neurosurgery Institute of the National Academy of Medical Science of Ukraine, Kiev, Ukraine \\ ${ }^{2}$ Romodanov Neurosurgery Institute of the National Academy of Medical Science of Ukraine, Kiev, Ukraine \\ ${ }^{3}$ Department of Physical and Technological Bases of Sensor Material Science, V. Ye. Lashkaryov Institute of Semiconductor of National \\ Science Academy of Ukraine, Kiev, Ukraine \\ ${ }^{4}$ Clinical Department, Romodanov Neurosurgery Institute of the National Academy of Medical Science of Ukraine, Kiev, Ukraine \\ ${ }^{5}$ Experimental Department, Romodanov Neurosurgery Institute of the National Academy of Medical Science of Ukraine, Kiev, Ukraine
}

Email address:

gridinanina@ukr.net (N. Gridina),a.n.m@ukr.net (A. Morozov), ushyuriy68@gmail.com (Y.Ushenin), rozumenko neuro@gmail.com (V. Rozumenko),exlab@gmail.com (N. Draguntsova)

\section{To cite this article:}

Nina Gridina, Anatoliy Morozov, Yuriy Ushenin, Vladimir Rozumenko, Nataliya Draguntsova. Treatment of Patients with Glioblastomas by Low Concentrations of Verapamil Hydrochloride in the Late Postoperative Period. Cancer Research Journal.

Vol. 7, No. 3, 2019, pp. 101-105. doi: 10.11648/j.crj.20190703.14

Received: July 5, 2019; Accepted: August 12, 2019; Published: August 23, 2019

\begin{abstract}
Antitumor effect of calcium channel blockers low concentrations has been investigated on the example of verapamil hydrochloride in the combined treatment of patients with glioblastomas after operation. Patients, who underwent brain tumor surgery, postoperative radiotherapy and chemotherapy, were divided into two groups. The first group of 11 patients was taken by verapamil - hydrochloride in low concentrations, the second group (32 patients) served as a control. The concentration of the drug was selected individually by means of peripheral blood cells aggregation data on the "Plasmon-6" biosensor. The criterion for the drug concentration selecting was the lowest level of peripheral blood cells aggregation in vitro, reflecting the level of NMDA-dependent calcium channels blocking of the peripheral blood cells membranes. The optimal concentration of verapamil - hydrochloride for all patients was less than 10,000. The criteria of the antitumor activity of verapamil-hydrochloride in low concentrations was the length of the patients life in the postoperative period. When using the drug in patients there were no signs of toxic effects of verapamil - hydrochloride on the body, life expectancy was 10 months more compared to the group of patients not treated with verapamil - hydrochloride and the absence of the toxic and tumorstimulating action of the drug.
\end{abstract}

Keywords: Glioblastomas, Tumor-Associated Inflammation, Low Concentrations of Verapamil-Hydrochloride, Life Expectancy

\section{Introduction}

The complexity of treating human malignant tumors lies in the lack of an objective understanding of the tumor growth mechanism. Brain gliomas are one of the most malignant human tumors with an unfavorable prognosis and a short period of life in the postoperative period, averaging 9 months [1-3]. Among the many hypotheses we use in our work idea of tumor growth as a violation at the system level of the relationship between the mechanisms of reparation (the predominance of the inflammatory process) and regeneration (replacement of the defect with stem cells). The essence of these global processes in the body is that with chronic inflammatory processes that are not able to restore the structure and function of cells or tissues of the body, the regeneration mechanism is activated, which, due to stem cells, more effectively restores the viability of the destroyed tissues and organs. Tumor growth begins in the event of a conflict between these two processes, when the transition of repair to regeneration is incomplete and the process of stem cell development is adversely affected by cells and factors of 
inflammatory genesis over a fairly long time. In the body, there are mechanisms of protection against such effects on stem cells as apoptosis, which dominates during embryonic development, and the epithelial-mesenchymal transition (EMT) [4-5].

As is known, the embryo in a woman's body develops in isolation from outside inflammatory exposure. In addition, almost all parenchymal organs subjected to regeneration processes have their own protective barriers, among which the blood-brain barrier is the most impenetrable.

Based on this idea of malignant growth, the study of the inflammatory process that accompanies the growth of malignant gliomas, called tumor-associated inflammation (TAI), becomes relevant [6-9]. In our previous studies, a relationship was found between the increased inflammatory component and the increase in the degree of glioma malignancy [10]. Therefore, the use of methods for inhibiting TAI in the postoperative period acquires considerable interest in order to prevent possible continued gliomas growth. Most anti-inflammatory drugs have a number of side effects and are not recommended for long-term use in patients with malignant tumors. Suppression of TAI can be accomplished by reducing the activity of ionotropic receptors, such as NMDA - receptors [11-13].

The structure of NMDA- receptors includes calcium channels. Calcium ions are essential in the development of the inflammatory process in the body, in many pathological processes, including tumors. The inhibition of TAI using NMDA-dependent calcium blocker verapamil can help to slow the growth of glioblastomas, without causing toxic effects on the body with prolonged use.

Objective: to investigate the life expectancy of patients with glioblastomas in the distant postoperative period in the treatment with concentrations of verapamil - hydrochloride, which minimize the level of aggregation of blood cells in stage II of the inflammatory process.

\section{Materials and Methods}

Patients were treated in the clinic with intracerebral tumors Among enrolled 28 patients were with primary diagnosed intracerebral tumors and 15 patients with continued tumor growth.

After surgical removal, all tumors were histologically verified as isomorphous cell glioblastomas. The patients were divided into 2 groups that received (group I) or who did not receive treatment (group II) with a calcium blocker using the example of verapamil - hydrochloride. The average age of patients in the I-th group was $56.2 \pm 7.8$ years, and in the IInd group $-55.8 \pm 7.9$ years.

For the objectification of the TAI presence in the patient's body, the definition of aggregation of blood cells was used (stage II of the inflammatory process). Venous blood with heparin taken from patients prior to the start of treatment was separated by centrifugation $(1500 \mathrm{rpm})$ for 10 minutes into the cellular elements of the blood and plasma. Heparin as is known not affect the level of blood cells aggregation. The cell fraction was used to determine the shift of the minimum of the surface plasmon resonance (SPR) curve in degrees, which reflects the level of aggregation of blood cells on the Plasmon sensor. Patients studied the indicators of the level of aggregation of blood cells prior to the commencement of therapeutic and surgical effects, as well as before carrying out repeated operations in patients with continued tumor growth, as well as in patients with remission.

To reduce the level of blood cells aggregation, we developed a method in vitro using the blocker of NMDAdependent $\mathrm{Ca}^{2+}$ - ion channels on the example of verapamil.

Under physiological conditions, NMDA - receptors are known to be activated by millimolar concentrations of glutamate, which is present in the synaptic cleft for several milliseconds. In pathological impulses, receptors are activated by micromolar concentrations, but for a significantly longer time [14]. We took the same pattern as a basis for the effects of millimolar and micromolar concentrations of verapamil - hydrochloride on the level of blood cells aggregation, given the location of the calcium channel in the structure of the NMDA - receptors of lymphocytes and which function is NMDA-dependent. Selection of optimal concentrations of verapamil hydrochloride was carried out with the aim of treating patients with glioblastomas in the postoperative period.

Peripheral blood cells was collected from patients to determine the indicators of blood cells aggregation with the addition of various aqueous dilutions of verapamil hydrochloride (from 1:10 to 1: 100,000 times). This made it possible to indirectly determine the level of blocking of the NMDA-dependent calcium blocker verapamil on the membranes of blood cells, including leukocytes and lymphocytes [15]. Patients took drugs in the dosage at which the level of aggregation of blood cells was the lowest. Dosing of the drug was performed by reducing its concentration by a factor of 10,000 .

Of the 43 patients, admitted to the clinic, only three patients did not undergo chemotherapy. After the surgical removal of glioblastoma and the postoperative irradiation course (40-60Gy), they only took verapamil- hydrochloride at low concentrations daily.

Statistical processing of the data was performed in the "Statistica10v" package using non-parametric data evaluation methods. Evaluated the correctness of the distribution of signs for each of the obtained variation series, the average values for each characteristic were studied, and standard deviations. The reliability of the difference of values is between non-dependent quantitative values using the Man-Whitney U-test, and between dependent values using the Wilcoxon test.

\section{Results and Discussion}

In the group of patients undergoing combined treatment courses and taking verapamil, the average life expectancy was $18.6 \pm 1.82$ months. (table 1 ). 
Table 1. The life expectancy of patients receiving a course of treatment with verapamil - hydrochloride with a combined treatment of glioblastomas in the late postoperative period.

\begin{tabular}{lllll}
\hline Group & Number & Mean (months) & Standard & Median life expected \\
\hline Control & 32 & 8,47 & 1,02 & 7 \\
Treated with verapamil & 8 & 18,63 & 1,82 & 18 \\
\hline
\end{tabular}

The average life expectancy of patients, who did not take verapamil, but only the combined treatment in the postoperative period, was $8.47 \pm 1.02$ months. (Figure 1). The total number of patients, who lived more than one year after surgery and did not take verapamil, was $29 \%$. The number of patients taking verapamil, along with chemotherapy and radiation, who lived more than a year after surgery, was $100 \%$.

Patients without chemotherapy (3 people) in the postoperative period received daily treatment with verapamil hydrochloride without interruption. All 3 patients continue to live for 18, 24 and 28 months, respectively.

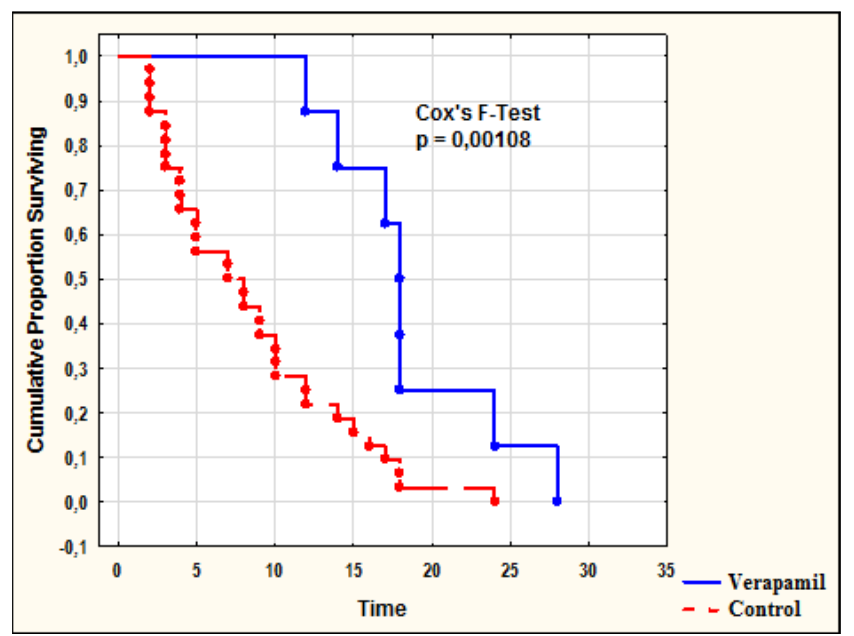

Figure 1. Differences between groups of patients, who received and did not receive verapamil treatment, are significant by the F-Cox test. The significance level is 0.001 .

Studies of the level of aggregation of blood cells were expressed in terms of SPR, which quantitatively reflected the level of the blood cells aggregation of patients, since nanoscale intercellular distances (of the order of 200-300 nm) in the flow cell between blood cells located on a glass plate covered with a thin layer were determined with high accuracy gold.

Baseline indicators of SPR before treatment with verapamil - hydrochloride in both groups of patients differ slightly, which indicates the adequacy of the selection of groups. In order to select the optimal concentration of verapamil - hydrochloride for treating patients, aqueous dilutions of verapamil - hydrochloride (from 1:10 to 1: 100.000 times) were added to the blood in vitro beforehand. Dilutions of verapamil tenfold led to an increase in the level of aggregation, and large dilutions of verapamil (10,000 times), on the contrary, contributed to a decrease in the aggregation of the blood cells. The concentration of verapamil - hydrochloride under the action of which noted the greatest decrease in the level of aggregation of the blood cells, was then used in the treatment of patients with glioblastomas in the postoperative period. Patients took a solution of the drug 3 times a day, constantly, without interruption, for life.

Indicators of SPR in patients of groups I and II are presented in Figure 2.

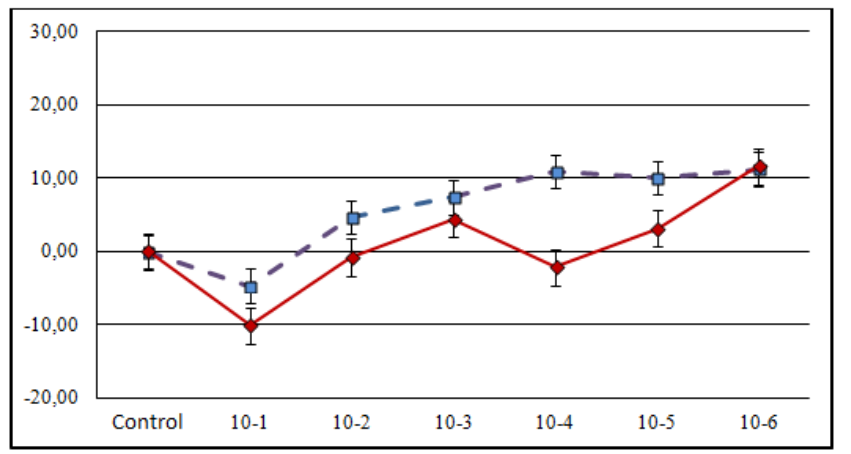

Figure 2. The ratio of blood cells aggregation indicators under the action of verapamil dilutions in patients with glioblastomas, treated and not treated with verapamil (line with a stroke). A comparison was made of SPR indices in relation to the indices of blood dilution with water $(20 \mu \mathrm{l}$ of water and 200 $\mu$ l of blood), with no hemolysis in any of these dilutions.

As can be seen from Figure 2, the decrease in the SPR curve under the action of verapamil, when diluted with water is 10,000 times, the same as postoperative remission in patients with glioblastomas, as evidenced by visualization methods performed. An increase in the SPR curve was observed in patients with recurrent glioblastoma.

The dependence of the blood cells aggregation level on the presence of a tumor in the brain is well expressed when verapamil is added to the blood at a dilution of 10,000 times (concentration $10^{-4}$ ), which leads to a decrease of SPR. This is characteristic of benign or conditionally benign tumors, such as meningiomas or glioma II grade of malignancy, which was shown in our previous studies [16].

Preliminary experiments to determine the level of aggregation of blood cells in patients with glioblastomas under the action of verapamil and ketamine, which is a selective blocker of NMDA - receptors, as well as in the treatment of experimental rats with a transplantable glioma of strain 101.8 (human glioblastoma analog) showed coincidence of data on the effect of verapamil and ketamine both on the level of patient cell aggregation in glioblastoma and on the life expectancy of experimental animals.

The action of ketamine was more effective than verapamil, but long-term use of ketamine in the clinic can be dangerous. This indicates a link between the mechanisms of blocking calcium channels by verapamil and a decrease in the activity 
of ionotropic NMDA - receptors, due to the structural feature of the NMDA- receptor containing the built-in calcium channel. Movalis, a nonsteroidal anti-inflammatory pharmacological drug, is a selective blocker of COX-2 (cyclooxygenase-2) and at a dilution of 10,000 times did not have an antitumor effect on rat glioma 101.8. Consequently, the effective inhibition of glioblastoma growth, obtained in the work, was achieved using the mechanisms of blocking the NMDA - receptor and the calcium channel on the membranes of glioblastoma cells and peripheral blood cells of patients, which leads to a change in the microenvironment of malignant brain tumors and inhibition of their growth.

All known methods of treatment of malignant tumors are aimed at cytoreduction and suppression of the tumor growth. Inflammation, contributing to an increase in cell mass with glioblastoma growth, is a protective-compensatory reaction that cannot be completely suppressed. To inhibit TAI in patients, it is necessary to act not on the third stage of inflammation with the mechanisms of proliferation, but on the first stage, on alteration, and to reduce the activity of calcium blockers and ionotropic NMDA - receptors. The latter activate inflammation and in the mechanisms of growth and destruction of brain cells during the tumor process play an important role, which can be indirectly determined by indicators of the level of the blood cells aggregation [16]. This is achieved by reducing the appearance of necrotic tissues by suppressing the activity of NMDA-dependent calcium channels by verapamil. Thereby, conditions are created in the tumor microenvironment to hinder the reproduction of glioblastoma cells. The use of verapamil in traditional doses does not provide the antitumor effect, which was noted in the animal experiments [17].

The effectiveness of such an approach to the treatment of glioblastomas can be compared with the data of other authors [18], in which, with early diagnosis of primary glioblastomas and new medical tactics, the life expectancy of patients averaged only 15.3 months.

The question of the adverse effect of calcium antagonists on the occurrence of cancer has been discussed. However, a critical analysis of data on the treatment of hypertension with these drugs allowed WHO experts to conclude that such information was unreasonable [19-20]. In addition, it was shown that with the introduction of certain carcinogens ( 7 , 12-dimethylbenzantracene) into animals, verapamil suppressed the development of tumors in rats [21]. Other researchers have shown the absence of tumor-stimulating activity of verapamil during prolonged exposure in rats [22]. As it known, the drug is used widely throughout the world for the treatment of cardiac arrhythmias, without showing pronounced adverse reactions. It was shown, that verapamil did not increase the risk of complications in patients after myocardial infarction [19].

Verapamil enhances the effectiveness of chemotherapy in patients [23]. The paper presents data on the treatment of 3 patients with glioblastomas only by verapamil, after irradiation courses, but without chemotherapy, which certainly indicates the presence of antitumor activity in this drug.

Traditional methods of glioblastoma treatment should be combined with techniques of low concentrations of verapamil hydrochloride in the late postoperative period, since the activation of TAI after chemotherapy and radiotherapy contributes to the growth of tumor residues in the brain. The results obtained can be used to decide the question of the individual tactics of treating a patient.

\section{Conclusion}

Any modern treatment of malignant tumors causes the appearance of necrosis in the tumor tissue, which are activators of the inflammatory process and continue to stimulate tumor growth in the postoperative period. Therefore, in the postoperative period, it is necessary to use anti-inflammatory drugs after any treatment of tumors. However, not all anti-inflammatory drugs can have an antitumor effect and be safe for the body with prolonged use. Preference should be given to those anti-inflammatory drugs that act on mechanisms or targets of inflammatory genesis involved in stage I of inflammation. Blocking targets that are synthesized in stage II or III of inflammation will be less effective, because then there will be many such compounds. Activation of ionotropic NMDA - receptors on blood cell membranes is one of the earliest events that triggered a huge cascade of synthesis of inflammatory compounds. Ketamine is one of the selective blockers of NMDA - receptors, but it is classified as a narcotic drug. At the same time, verapamil as calcium blocker NMDA-dependent channels is a safe drug suitable for long-term use, as shown by the practice of cardiovascular treatment diseases. A feature of the use of verapamil in malignant tumors is the fact that we are dealing with inflammation of the tumor origin - tumor-associated inflammation, which is microinflammation and is authored by necrotic tumors of the tumors. Therefore, with microinflammation and with the peculiarities of the release of glutamate, which activates ionotropic NMDA receptors, it is necessary to conduct an individual selection of verapamil concentrations. The screening of the concentration gradient of verapamil has become possible to carry out quickly and efficiently with the help of Plasmon series biosensors, which can determine the level of blood cell aggregation indirectly associated with the transmembrane potential, which changes upon modulation of ionotropic receptors of cell membranes. The concentration at which the lowest level of blood cell aggregation was observed was optimal for verapamil, which corresponded to a dilution of $40 \mathrm{mg}$ of verapamil 10,000 times taking into account weight correction.

The paper presents for the first time the results of treatment of highly malignant glioblastomas with low concentrations of the dependent calcium blocker verapamilhydrochloride. The results indicate a high antitumor activity of the drug, both when used together with traditional methods of treatment or separately. The absence of toxic manifestations of the drug, an increase in the duration and improvement of the quality of life in patients with 
glioblastomas treated with verapamil hydrochloride in the late postoperative period were introduced.

\section{References}

[1] Matsko DE. Neyrokhirurgicheskaya patologiya. SPb.: FGBU «RNKHI im. prof. A. L. Polenova» MZ Rossii; 2015. 424 p., Russian.

[2] Zozulya YuA, Vasil'yeva IG, Glavatskiy AYa, Rozumenko VD, Lisyaniy NI, Gridina NY. Sovremenniye tekhnologii konservativnogo lecheniya gliom. V: Zozulya YUA, red. Gliomy golovnogo mozga. Kiyev: UIPK "YeksOb"; 2007. pp. 383-509. Russian.

[3] Rozumenko AV., Kliuchka VM., Rozumenko VD., Fedorenko ZP. Survival rates in patients with the newly diagnosed glioblastoma: Data from National Cancer Registry of Ukraine, 2008-2016. Ukrainian Neurosurgical Journal. 2018; (2): 33-39. DOI: https://doi.org/10.25305/unj.124878.

[4] Thiery JP. Epithelial-mesenchymal transitions in tumour progression. Nat Rev Cancer. 2002; 2 (6): 442-454. PMID: 12189386. DOI: $10.1038 / \mathrm{nrc} 822$.

[5] [5 Polyak K, Weinberg RA. Transitions between epithelial and mesenchymal states: acquisition of malignant and stem cell traits. Nat Rev Cancer. 2009; 9 (4): 265-273. PMID: 19262571. DOI: $10.1038 /$ nrc2620.

[6] Luchnik AN. A common link in the mechanism of selfmaintenance of malignant growth: the syndrome of the nonhealing wound. Ontogenesis 2000; 31 (3): 227-231. English.

[7] Schwarzburd PM. Chronic inflammation increases risk of epithelial neoplasia by inducing precancerous microenvironment: an evaluation of pathways of disregulation. Problems in Oncology. 2006; 52 (2): 137-144. Russian.

[8] Mantovani A, Allavena P, Sica A, Balkwill F. Cancer-related inflammation. Nature. 2008 Jul; 454 (7203): 436-44. doi: 10. 1038/nature07205. Review. PubMed PMID: 18650914.

[9] Whiteside TL. The tumor microenvironment and its role in promoting tumor growth. Oncogene. 2008; 27 (45): 59045912. PMID: 18836471; PMCID: PMC3689267. DOI: 10. 1038/onc. 2008. 271.

[10] Gridina N, Maslov V, Ushenin Yu. Tumor-Associated Inflammation and Brain Glyomas. Saarbrücken, Lambert Academic Publishing; 2013. 186 p. Russian.

[11] Takano T, Lin JH, Arcuino G, Gao Q, Yang J, Nedergaard M. Glutamate release promotes growth of malignant gliomas. Nat Med. 2001 Sep; 7 (9): 1010-5. PubMed PMID: 11533703. DOI: $10.1038 / \mathrm{nm} 0901-1010$.

[12] Fu YS, Lin YY, Chou SC, Tsai TH, Kao LS, Hsu SY, Cheng FC, Shih YH, Cheng $\mathrm{H}$, Fu YY, Wang JY. Tetramethylpyrazine inhibits activities of glioma cells and glutamate neuro-excitotoxicity: potential therapeutic application for treatment of gliomas. Neuro Oncol. 2008 Apr;
10 (2): 139-52. doi: 10. 1215/15228517-2007-051. Epub 2008 Feb 26. PubMed PMID: 18314418; PubMed Central PMCID: PMC2613816.

[13] Gridina NYa. Utilizing SPR as a novel technique to measure cell aggregation for ketamine treated brain gliomas. Cancer Oncol. Res. 2013; 1 (1): 1-5. DOI: 10.13189/cor.2013.010101.

[14] Clements JD, Lester RA, Tong G, Jahr CE, Westbrook GL. The time course of glutamate in the synaptic cleft. Science. 1992 Nov; 258 (5087): 1498-501. PubMed PMID: 1359647. DOI: $10.1126 /$ science. 1359647.

[15] Davydova ON, Boldyrev AA. Glutamatniye retseptory v kletkakh nervnoy i immunnoy systems. Annaly klinicheskoy i eksperimental'noy nevrologii. 2007; 1 (4): 28-34. Russian.

[16] Gridina NYa, Shvachko LP, Draguntsova NG. Tumor-Associated Inflammation Mechanisms Correction by Verapamil at Brain Gliomas Progression. [Internet]. Eur J Pharmaceutic Med Res (EJPMR). 2016; 3 (8): 73-78 Available from: https://www.ejpmr.com/admin/assets/article_issue/146985497 9.pdf

[17] Gridina NYa, Maslov VP, Kotovsky VY, Draguntsova NG. Peculiarities of the Spectrum of Chromosome Aberrations in the Peripheral Blood Lymphocytes in Cases of Brain Gliomas and their Correction with Verapamil and Ketamine. [Internet]. Scholar Journal of Applied Medical Sciences (SJAMS). 2015 Sep; 3 (6A): 2156-2160. Available from: http://saspublishercom/wp-content/uploads/2015/09/SJAMS36A-2156-2160.pdf.

[18] 'Medyanik IA. New approaches to early diagnosis and treatment tactics for malignant brain tumors (wedge. experimental. Studies): author. dis. for nauch. degree doctor Sciences: specialist. 01/14/18 - Neurosurgery / AND. A. Medyanik; Federal State Institution "Volga Federal Medical Research Center" of the Ministry of Health of the Russian Federation. - Nizhny Novgorod, 2016. - 40 p.

[19] Karpov YuA, Soboleva GN. Calcium antagonists - first-line drugs in modern cardiology (2 part). Terapevt. arkhiv. 1997; 69 (1): 74-78. Russian.

[20] Mokhort NA, Seredinskaya NN, Bobkova LS. Calcium antagonists: prospects for new medical preparations development (review of literature). Journal AMS of Ukraine. 2003; 9 (1): 15-27. Russian.

[21] Soybir G, Köksoy F, Koyuncu H, Yalçin O, Köse H, Topuzlu C. Chemoprevention of DMBA-induced mammary gland carcinogenesis - preventive effects of free oxygen radical scavengers. Breast Cancer Res Treat. 1998 Jul; 50 (2): 193-9. PubMed PMID: 9822224. DOI: 10. 1023/A:1005701116297.

[22] Dunn AJ, Faust J, Krowech G. Evidence on the carcinogenicity of verapamil. [Internet]. California: OEHHA; 2004. 45 p. Available from: https://oehha.ca.gov/media/downloads/proposition65/chemicals/hidverapamil.pdf

[23] Helson L. Calcium channel blocker enhancement of anticancer drug cytotoxicity - a review. Cancer Drug Deliv. 1984; 1 (4): 353-61. Review. PubMed PMID: 6100477. 